\title{
Reframing Quality of Care Discussions in Surgery: Shifting from Surgeon Focus to Patient Perspectives
}

\author{
Michelle R. Ju, MD, and Matthew R. Porembka, MD \\ Division of Surgical Oncology, Department of Surgery, University of Texas Southwestern Medical Center, Dallas, TX
}

Since the 1980s, the outcomes movement has gained traction as a means of improving health care quality while restraining the growing healthcare expenditure within the US. ${ }^{1}$ Dr. Donabedian conceptualized one of the earliest frameworks for assessing and defining quality of care, which defined three key components: structure, process, and outcome. ${ }^{2}$ Structure relates to characteristics of providers or facilities, such as surgeon experience, the ratio of nurses to patients, and hospital size. Process indicates the conduct of healthcare delivery, such as receipt of appropriate preoperative antibiotics or deep venous thrombosis prophylaxis. Finally, outcome assessments measure the results of a patient's healthcare experiences. Simply put, how did the patient do?

In the past, quality research within surgery primarily focused on outcomes. However, outcome measures, unlike structure and process measures, can be difficult to define and assess. Measures of patient satisfaction of function, symptom improvement, or quality of life postsurgery are often elusive and not standardized. Therefore, outcomes in surgery have been primarily measured by enumerating complications and their severity. As the field of quality research evolves, an opportunity arises to evaluate outcomes from the patient perspective rather than from the surgeon's. After all, it is our patients who ultimately live the experiences of their healthcare outcomes.

(C) Society of Surgical Oncology 2020

First Received: 15 June 2020

Accepted: 19 June 2020;

Published Online: 8 July 2020

M. R. Porembka, MD

e-mail: matthew.porembka@utsouthwestern.edu
In the article "Patient Satisfaction Dictated by Quality of Care among Patients Undergoing Complex Surgical Procedures for a Malignant Indication?" Mehta et al. explore the impact of patient satisfaction on healthcare outcomes among surgical patients with colorectal, lung, esophageal, liver, and pancreatic cancers using data from the Medicare Inpatient Standard Analytical Files (SAFs) and the Hospital Consumer Assessment of Healthcare Providers and Systems (HCAHPS) survey. ${ }^{3}$ The authors investigate all three components of quality of care, correlating structure, process, and outcome measures to achievement of optimal patient satisfaction and the subsequent impact of patient satisfaction scores on 90-day postoperative mortality and readmissions. Hospital factors such as urban location, higher surgical volume, and increased nursing ratios were also associated with higher likelihood of optimal patient satisfaction. Using a novel approach, composite Textbook Outcome (TO) quality metric was linked with patient satisfaction scores. Hospitals with the highest patient-satisfaction scores had the highest proportion of surgical cases that achieved TO. Poor patient-satisfaction scores were associated with increased 90-day postoperative mortality and readmissions. They concluded that high-quality care as measured by TO is associated with patient satisfaction, which in turn, leads to improved patient outcomes following cancer surgery.

This study identifies several key factors linked with patient satisfaction and demonstrates the impact of patient satisfaction on outcomes. Table 1 describes four commonly used quality measurement systems and their various advantages/limitations. All four systems rely on capturing postoperative complications. However, we must ask ourselves: Are complications the right outcome measure? A 2016 study conducted at the Washington University School of Medicine anesthesiology department found poor positive agreement between patient recall of complications and 
TABLE 1 Commonly utilized quality measure systems

\begin{tabular}{|c|c|c|c|}
\hline $\begin{array}{l}\text { Quality measure } \\
\text { system }\end{array}$ & Factors assessed & Advantages & Limitations \\
\hline $\begin{array}{l}\text { National Surgical } \\
\text { Quality } \\
\text { Improvement } \\
\text { Program } \\
\text { (NSQIP) }\end{array}$ & $\begin{array}{l}\text { Measures 30-day morbidity and } \\
\text { mortality for a defined set of } \\
\text { procedures }\end{array}$ & $\begin{array}{l}\text { Having dedicated abstractors with } \\
\text { rigorous definitions results in } \\
\text { excellent capture }\end{array}$ & $\begin{array}{l}\text { Most participating centers only } \\
\text { sample a small subset of the total } \\
\text { number of surgical cases } \\
\text { Capture of complications does not } \\
\text { extend beyond } 30 \text { days } \\
\text { postoperatively } \\
\text { No stratification of complication } \\
\text { severity }\end{array}$ \\
\hline $\begin{array}{l}\text { Clavien-Dindo } \\
\text { (CD) } \\
\text { Classification }^{9}\end{array}$ & $\begin{array}{l}\text { Classifies complications into five grades } \\
\text { based on severity and potential for } \\
\text { long-lasting disability after discharge }\end{array}$ & $\begin{array}{l}\text { Commonly used } \\
\text { Simple to use } \\
\text { Standardized scale allows for easy } \\
\text { comparison between } \\
\text { surgeons/facilities }\end{array}$ & $\begin{array}{l}\text { Wide range of complications captured } \\
\text { within each grade, which may be } \\
\text { interpreted as having different true } \\
\text { severities (e.g., grade III } \\
\text { complications that require "surgical } \\
\text { intervention" vary widely) }\end{array}$ \\
\hline $\begin{array}{l}\text { Accordion Severity } \\
\text { Grading System/ } \\
\text { Post-Operative } \\
\text { Morbidity } \\
\text { Index }^{10}\end{array}$ & $\begin{array}{l}\text { Relies on surgeon assessment of } \\
\text { complication number and } \\
\text { burden/severity to stratify } \\
\text { postoperative morbidity into grades }\end{array}$ & $\begin{array}{l}\text { Provides an aggregate measure of } \\
\text { complication severity }\end{array}$ & $\begin{array}{l}\text { Relies on qualitative terms to classify } \\
\text { complications } \\
\text { Does not consider intraoperative } \\
\text { events }\end{array}$ \\
\hline $\begin{array}{l}\text { Composite } \\
\text { Textbook } \\
\text { Outcome (TO) }\end{array}$ & $\begin{array}{l}\text { Composite measure of multiple outcome } \\
\text { parameters reflecting the "ideal" } \\
\text { surgical outcome for various } \\
\text { procedures which produces a binomial } \\
\text { outcome (achieved/not achieved) }\end{array}$ & $\begin{array}{l}\text { Used to infer complications from } \\
\text { large administrative databases } \\
\text { which may not specifically capture } \\
\text { postoperative complications }\end{array}$ & $\begin{array}{l}\text { Not standard across different surgical } \\
\text { fields } \\
\text { Achievement of "ideal" surgical } \\
\text { outcome may not equate with } \\
\text { "ideal" outcome from patient } \\
\text { perspective }\end{array}$ \\
\hline
\end{tabular}

complications documented in the medical record at $\geq 30$ days postprocedure (range $0-55 \%) .{ }^{4}$ These results did not change significantly when patients were stratified by sex or age. Given patients often are unable to identify and recall their own complications, linking patient-centered outcome measures to quality markers may require metrics besides surgical complications.

A recent systematic review conducted as part of the Standardised Endpoints in Perioperative Medicine (StEP) initiative identified a long list of patient-centered outcome measures used in previously published perioperative medicine studies. ${ }^{5}$ After a Delphi consensus process, five common themes were identified: patient satisfaction, health-related quality of life, functional status, patient wellbeing, and life impact. The panel recommended that one health-related quality of life measure (EuroQol 5 Dimension), one functional status measure [World Health Organization (WHO) Disability Assessment Schedule], and one life-impact measure (such as traditional 30-day morbidity/mortality markers) be included as endpoints in all peri-operative outcomes research. However, collecting this type of data mandates a prospective process, which can be burdensome and resource intense. ${ }^{6}$ Selecting the appropriate timepoint to measure these outcomes is also difficult, as quality of life and functional status evolve dynamically with time. Additionally, the use of general patient-reported outcome measures (PROMs) versus condition-specific PROMs is also debated. Generic PROMs allow outcomes to be compared across different types of operations based on shared functional measures, such as ability to complete housework. However, these provide less granular insight into a patient's perceptions of their postsurgical outcomes. Condition-specific PROMs allows for a much deeper understanding of a patient's perspectives. One example is the BODY-Q, ${ }^{7}$ which was designed for obese patients undergoing bariatric surgery and includes evaluation of body image, effect of excess skin, and psychosocial health. Although condition-specific PROMs are highly useful for evaluating outcomes associated with a single treatment/surgical approach, these lack standardization, are difficult to validate, and are unable to be translated across various surgical fields.

While it is clear that patient perceptions of their own outcomes need to be incorporated into our quality measures, the optimal method for doing so remains elusive. With thousands of different PROMs being developed, the challenge will be balancing generic with condition-specific measures, and ensuring validity, inter-rater reliability, testretest reliability, and ease of data capture. Developing a core outcome set will reduce heterogeneity and variation in 
content and allow for improved standardization of reporting across different studies within the same area of interest, such as colorectal cancer. ${ }^{8}$ We must also ensure that PROMs are validated in diverse populations to ensure accurate capture of patient perspectives across racial/ethnic groups and cultural standards. With more patients interfacing with their health systems via electronic methods, this may represent an opportunity to build electronic collection of outcomes data into standard patient interactions; For example, patients may be asked to fill out an outcomes survey at their first postoperative visit in the same manner they currently provide a review of systems.

As Mehta et al. showed, optimizing patient satisfaction is associated with better outcomes. Although the study moves beyond commonly used surgeon-centric variables and attempts to integrate patient reported satisfaction, it lacks true patient-centered measures available in current widely used quality measurement systems. As the field of surgery continues to lead the efforts in optimizing quality, we will need to continue to move from surrogate markers of patient satisfaction to methods that capture the patient's perspectives. Building upon our several decades-long experience in measuring outcomes, continued innovation in data collection techniques and integration of patient outcome measures into standardized practice will move us closer toward achieving our goal.

DISCLOSURES The authors declare no conflicts of interest.

\section{REFERENCES}

1. Relman AS. Assessment and accountability: the third revolution in medical care. N Engl J Med. 1988;319(18):1220-2. https://doi. org/10.1056/nejm198811033191810.

2. Donabedian A. The quality of care. How can it be assessed? JAMA. 1988;260(12):1743-8. https://doi.org/10.1245/s10434-02 0-08788-w.
3. Mehta R, Tsilimigras, D. Paredes, A, Dillhoff, M, Cloyd, J, Ejaz, A, Tsung, A, Pawlik, T. Is patient satisfaction dictated by quality of care among patients undergoing complex surgical procedures for a malignant indication? Ann Surg Oncol. 2020. https://doi.org/ 10.1001/jama.260.12.1743

4. Fritz BA, Escallier KE, Ben Abdallah A, Oberhaus J, Becker J, Geczi $\mathrm{K}$ et al. Convergent validity of three methods for measuring postoperative complications. Anesthesiology. 2016;124(6): 1265-76. https://doi.org/10.1097/aln.0000000000001108.

5. Moonesinghe SR, Jackson AIR, Boney O, Stevenson N, Chan MTV, Cook TM et al. Systematic review and consensus definitions for the Standardised Endpoints in Perioperative Medicine initiative: patient-centred outcomes. $\mathrm{Br} J$ Anaesth. 2019; 123(5):664-70. https://doi.org/10.1016/j.bja.2019.07.020.

6. Van Der Wees PJ, Nijhuis-Van Der Sanden MW, Ayanian JZ, Black N, Westert GP, Schneider EC. Integrating the use of patient-reported outcomes for both clinical practice and performance measurement: views of experts from 3 countries. Milbank Q. 2014;92(4):754-75. https://doi.org/10.1111/1468-0009.12091.

7. Klassen AF, Cano SJ, Alderman A, Soldin M, Thoma A, Robson $\mathrm{S}$ et al. The BODY-Q: a patient-reported outcome instrument for weight loss and body contouring treatments. Plast Reconstr Surg Glob Open. 2016;4(4):e679. https://doi.org/10.1097/gox.000000 0000000665.

8. McNair AG, Whistance RN, Forsythe RO, Rees J, Jones JE, Pullyblank AM et al. Synthesis and summary of patient-reported outcome measures to inform the development of a core outcome set in colorectal cancer surgery. Colorectal Dis. 2015;17(11): O217-29. https://doi.org/10.1111/codi.13021.

9. Dindo D, Demartines N, Clavien PA. Classification of surgical complications: a new proposal with evaluation in a cohort of 6336 patients and results of a survey. Ann Surg. 2004;240(2): 205-13. https://doi.org/10.1097/01.sla.0000133083.54934.ae.

10. Porembka MR, Hall BL, Hirbe M, Strasberg SM. Quantitative weighting of postoperative complications based on the accordion severity grading system: demonstration of potential impact using the american college of surgeons national surgical quality improvement program. J Am Coll Surg. 2010;210(3):286-98. h ttps://doi.org/10.1016/j.jamcollsurg.2009.12.004.

Publisher's Note Springer Nature remains neutral with regard to jurisdictional claims in published maps and institutional affiliations. 